\title{
ARTICLE
}

\section{Measurement of radiation and radioactivity in KEK Tsukuba-campus after Fukushima No. 1 Nuclear Power Plant accident}

\author{
Hajime Nakamura*, Yoshihito Namito, Akihiro Toyoda, Kazuhiko Iijima and Kenichi Hozumi \\ High Energy Accelerator Research Organization (KEK), 1-1 Oho, Tsukuba-shi, Ibaraki-ken, 305-0801, Japan
}

\begin{abstract}
The radioactivity released by the Fukushima Daiichi No.1 Nuclear Plant accident was measured at the Tsukuba-campus of the High Energy Accelerator Research Organization (KEK). The Tsukuba-campus is located $\sim 165 \mathrm{~km}$ south-southwest of the Fukushima nuclear plant. We set up several measurement points in the Tsukuba-campus and measured the time variation of the radiation dose over a year by using an NaI survey meter and an $\mathrm{LaBr}_{3}$ spectrometer. We measured the radioactivity concentrations in soils and dried grasses by using a germanium semiconductor detector with In-Situ Object Calibration Software (ISOCS). On April 1, 2011 , the dose rate without a roof was $\sim 50 \%$ higher than that with a roof owing to rain. With regard to the difference on the ground surface, on April 11, 2011, the dose rate on turf was $20 \%$ higher than that on tiles. However, since the end of May 2011, it became lower than that on tiles. On March 18, 2011, the radioactivity concentration of ${ }^{131} \mathrm{I}$ in dried grasses and in soils was 109 and $0.8 \mathrm{~Bq} / \mathrm{g}$, respectively. On March 18, 2011, the radioactivity concentration of ${ }^{134} \mathrm{Cs}$ and ${ }^{137} \mathrm{Cs}$ in soils was 0.04 and $0.03 \mathrm{~Bq} / \mathrm{g}$, respectively; on April 1, 2011, the radioactivity concentration was 0.11 and $0.11 \mathrm{~Bq} / \mathrm{g}$, respectively.
\end{abstract}

\section{Keywords: Fukushima Nuclear Plant accident; environmental radiation measurements}

\section{Introduction}

On March 15, 2011, the first influence of the Fukushima No. 1 nuclear power plant accident was observed at the Tsukuba-campus of the High Energy Accelerator Research Organization (KEK). This campus, which is $2-\mathrm{km}$ long and $1-\mathrm{km}$ wide, is located $\sim 165 \mathrm{~km}$ south-southwest of the plant. After the Great East Japan Earthquake on March 11, 2011, only one radiation monitor could be run at the campus because of a shortage of electricity.[1] Subsequently, from April 1, 2011, we prepared to another measurement system and started to measure the radiation regularly.

\section{Measurement}

\subsection{Measurement of radioactivity concentrations in soils, dried grass and rain}

On March 18 and April 1, we sampled soils near the Radiation Science Center of KEK. Soil samples weighing 83.1 and $64.9 \mathrm{~g}$ were collected on these respective days from the ground surface by using a cylindrical container with a cross-sectional area and height of $25.5 \mathrm{~cm}^{2}$ and $3.4 \mathrm{~cm}$, respectively. Figure 1 shows dried grass, specifically, narrow leaves and stems, weighing $6.1 \mathrm{~g}$ taken from the ground surface near the sample soils on March 18. On March 21, Rainwater sample weighting $88.4 \mathrm{~g}$ was taken from rainwater collected in a bucket that was placed near sample soils.

The samples were measured using a germanium semiconductor detector (Canberra GR2018) with In-Situ Object Calibration Software.

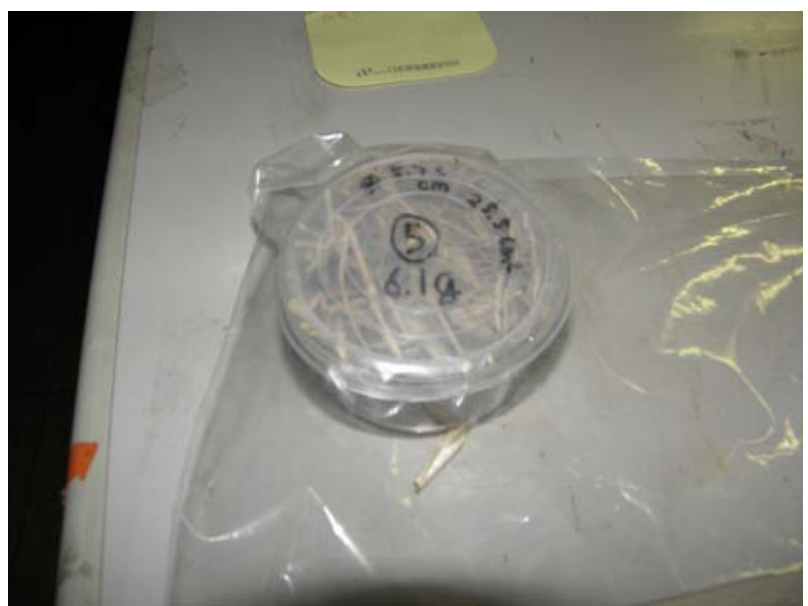

Figure 1. Sample of dried grass in 5.7-cm-diameter cylindrical container.

*Corresponding author. Email: hajime.nakamura@kek.jp 


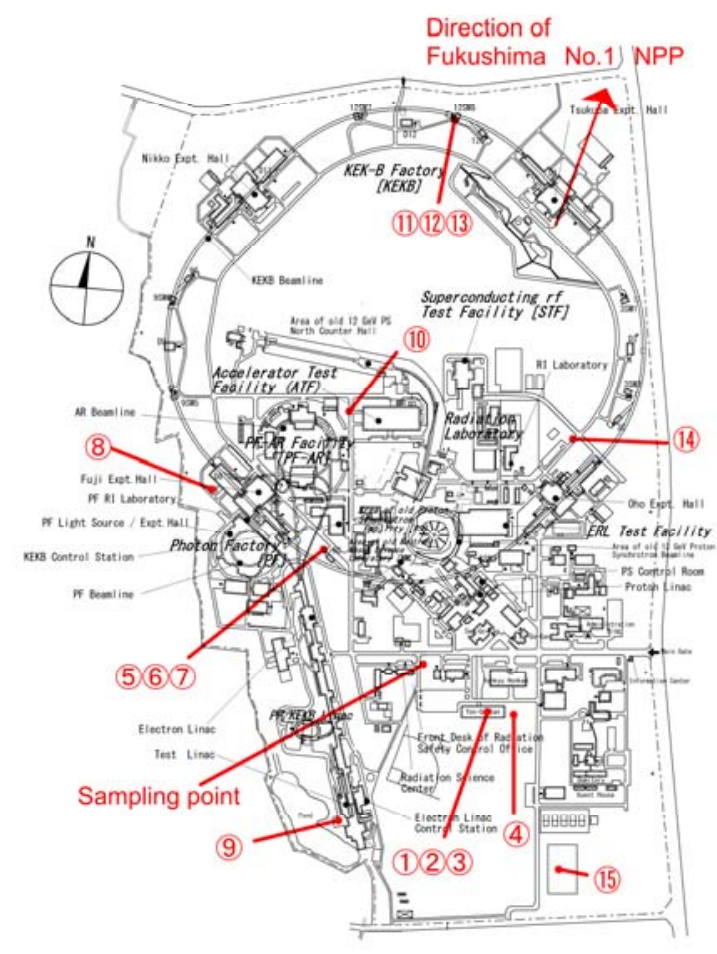

$\underbrace{0.100200300400}$

Figure 2. Map of measurement points and sampling points in KEK Tsukuba-campus.

\subsection{Measurement of ambient dose rate}

We set up 15 measurement points in the campus on different surfaces such as soils, tiles, lawns, dried grass, and normal asphalt (impermeable to water) with and without a roof. Figures $\mathbf{2}$ and $\mathbf{3}$ show the locations and photographs of the measurement points, respectively. We used an NaI scintillation survey meter (Aloka TCS-171B) and performed measurements on the ground and at $1-\mathrm{m}$ height from the ground. We performed 13 measurements from April 1, 2011, to Jun 11, 2012. Measurement point No. 7 is in a building, and it was used as a reference before the accident.

\subsection{Measurement of gamma-ray spectrum}

We measured the gamma-ray spectrum at the measurement points on the ground by using an $\mathrm{LaBr}_{3}$ spectrometer (Canberra Inspector 1000). Each measurement lasted 200 seconds.

\section{Results and discussion}

\subsection{Radioactivity concentrations in soils, dried grass and rainwater}

Table 1 shows the radioactivity concentrations in soils and dried grass as obtained on March 18, 2011 and in soils as obtained on April 1, 2011. On March 18, the radioactivity concentration in dried grass was greater than that in soils. In particular, the radioactivity concentration of ${ }^{131} \mathrm{I}$ in dried grass was 135 times larger than that in soils. This suggests that dried grass, which has a larger surface area per weight, absorbs more radioactivity.
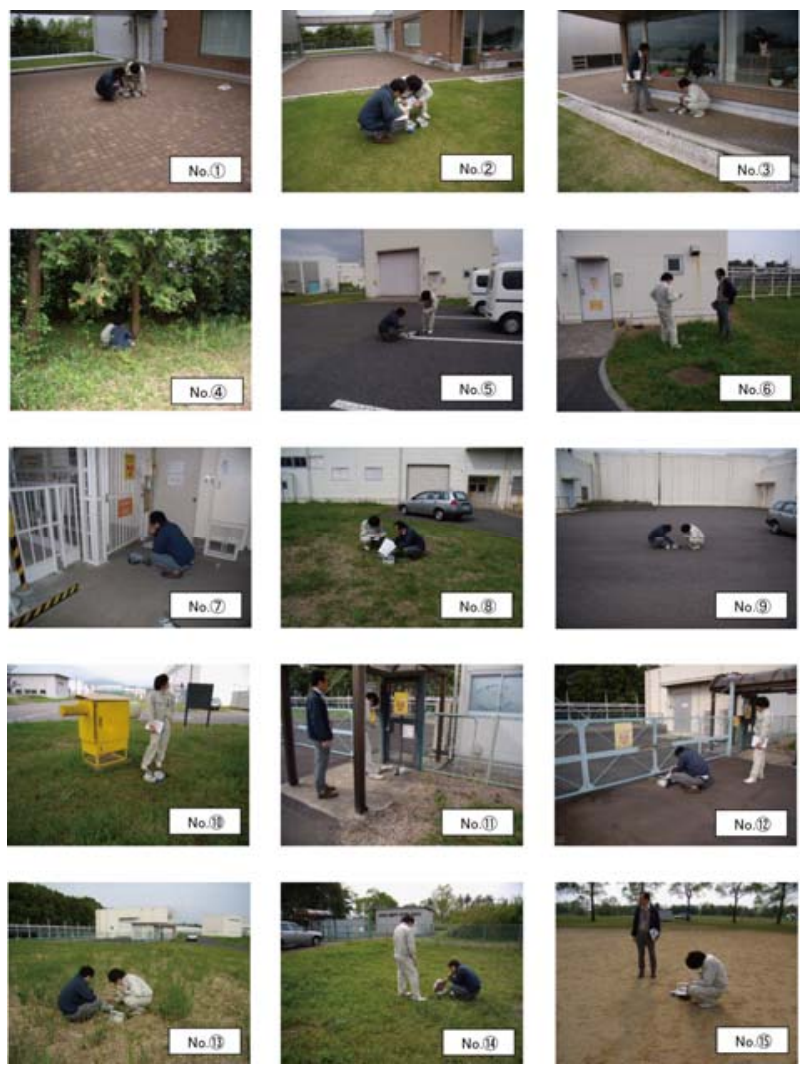

Figure 3. Photographs of measurement points. Measurement points No. 3, 7 and 11 were roofed locations. Specifically, measurement point No. 7 was in a building that was used as a reference before the accident.

Table 1. Radioactivity concentrations $(\mathrm{Bq} / \mathrm{kg})$ in soils and dried grass.

\begin{tabular}{cccc}
\hline $\begin{array}{c}\text { Date of } \\
\text { sampling }\end{array}$ & 18 -Mar & $18-\mathrm{Mar}$ & 1 -Apr \\
\hline Sample & Soils & Dried grass & Soils \\
\hline${ }^{134} \mathrm{Cs}$ & $3.7 \mathrm{E} 1 \pm 3 \mathrm{E} 0$ & $1.64 \mathrm{E} 3 \pm 1.6 \mathrm{E} 1$ & $1.11 \mathrm{E} 2 \pm 4 \mathrm{E} 0$ \\
${ }^{136} \mathrm{Cs}$ & $<1.1 \mathrm{E} 1$ & $2.75 \mathrm{E} 2 \pm 7 \mathrm{E} 0$ & $9.6 \mathrm{E} 0 \pm 2.5 \mathrm{E} 0$ \\
${ }^{137} \mathrm{Cs}$ & $2.8 \mathrm{E} 1 \pm 5 \mathrm{E} 0$ & $1.57 \mathrm{E} 3 \pm 3.4 \mathrm{E} 1$ & $1.05 \mathrm{E} 2 \pm 5 \mathrm{E} 0$ \\
${ }^{131} \mathrm{I}$ & $8.07 \mathrm{E} 2 \pm 1.6 \mathrm{E} 1$ & $1.089 \mathrm{E} 5 \pm 1.3 \mathrm{E} 2$ & $9.04 \mathrm{E} 2 \pm 1.1 \mathrm{E} 1$ \\
${ }^{132} \mathrm{I}$ & $9.7 \mathrm{E} 1 \pm 6 \mathrm{E} 0$ & $3.97 \mathrm{E} 3 \pm 3.1 \mathrm{E} 1$ & $2.68 \mathrm{E} 1 \pm 2.3 \mathrm{E} 0$ \\
${ }^{133} \mathrm{I}$ & $1.6 \mathrm{E} 1 \pm 3 \mathrm{E} 0$ & $1.03 \mathrm{E} 3 \pm 1.5 \mathrm{E} 1$ & $<3 \mathrm{E} 0$ \\
${ }^{140} \mathrm{La}$ & $<7 \mathrm{E} 0$ & $7.0 \mathrm{E} 1 \pm 7 \mathrm{E} 0$ & $<6 \mathrm{E} 0$ \\
${ }^{99 \mathrm{~m}} \mathrm{Tc}$ & $<5 \mathrm{E} 0$ & $7.4 \mathrm{E} 1 \pm 8 \mathrm{E} 0$ & $<2 \mathrm{E} 1$ \\
${ }^{129 m} \mathrm{Te}$ & $<2 \mathrm{E} 2$ & $1.72 \mathrm{E} 3 \pm 2.8 \mathrm{E} 2$ & $<1.6 \mathrm{E} 1$ \\
${ }^{132} \mathrm{Te}$ & $1.04 \mathrm{E} 2 \pm 5 \mathrm{E} 0$ & $4.34 \mathrm{E} 3 \pm 3.3 \mathrm{E} 1$ & $3.6 \mathrm{E} 1 \pm 2 \mathrm{E} 0$ \\
\hline
\end{tabular}

The radioactivity concentrations of ${ }^{134} \mathrm{Cs}$ and ${ }^{137} \mathrm{Cs}$ as obtained on April 1 were greater than those obtained on 
March 18. The radioactivity concentrations of ${ }^{134} \mathrm{Cs}$, ${ }^{137} \mathrm{Cs},{ }^{131} \mathrm{I}$ and ${ }^{132} \mathrm{I}$ in rainwater were $93.1 \pm 6.8,96.3 \pm 9.9$, $856 \pm 22$ and $150 \pm 9 \mathrm{~Bq} / \mathrm{kg}$, respectively. This suggests that the rain on March 21 and 22 gave the radioactivity to the soils.[2]

\subsection{Ambient dose rate}

Figures 4 and 5 show the ambient dose rates on the ground and at 1-m height from the ground, respectively. The dose rates on the ground were slightly higher than those at 1-m height from the ground. From April 1, 2011, to Jun 12,2012 , the ratio of the dose rate on the ground to those at 1-m height from the ground (except at reference measurement point No. 7) was $1.13 \pm 0.04$. On April 1, 2011, the dose rate at 1-m height from the ground was $0.16-0.25 \mu \mathrm{Sv} / \mathrm{h}$. In a month, the effective half-life was $\sim 10$ days. By December 22, 2011, the dose rate decreased, being $0.08-0.12 \mu \mathrm{Sv} / \mathrm{h}$.

Figure 6 shows a comparison of the dose rates on tiles with a roof to those on tiles without a roof. On April 1, 2011, the dose rate without a roof was $\sim 50 \%$ higher than that with a roof, which clearly indicates the effect of rain.
Figure 7 shows a comparison of the dose rates on tiles to those on lawns. On April 1, 2011, the dose rate on lawns was $\sim 20 \%$ higher than that on tiles. After May 26,2011 , the dose rate on lawns was lower than that on tiles.

Figure 8 shows a comparison of the dose rates on dried grass and soils to that on asphalt. On April 1, 2011, the dose rate on dried grass and soils was higher than that on asphalt, but after April, the reverse was true.

\subsection{Gamma-ray spectrum}

Figure 9 shows the spectra at measurement point No. 4 from April 1, 2011, to June 11, 2012. During April and May 2011, ${ }^{131} \mathrm{I},{ }^{134} \mathrm{Cs}$, and ${ }^{137} \mathrm{Cs}$ peaks were observed, after which only ${ }^{134} \mathrm{Cs}$ and ${ }^{137} \mathrm{Cs}$ peaks were observed

Figure 10 shows the spectrum at measurement point No.1 (tiles) and No.2 (lawns) on April 9, 2011. ${ }^{131}$ I peaks at lawns were greater than that at tiles. However, ${ }^{134} \mathrm{Cs}$ and ${ }^{137} \mathrm{Cs}$ peaks at lawns and those at tiles were almost same. In April, the lawns appeared to absorb a lot of radioactivity owing to the effect of ${ }^{131} \mathrm{I}$.

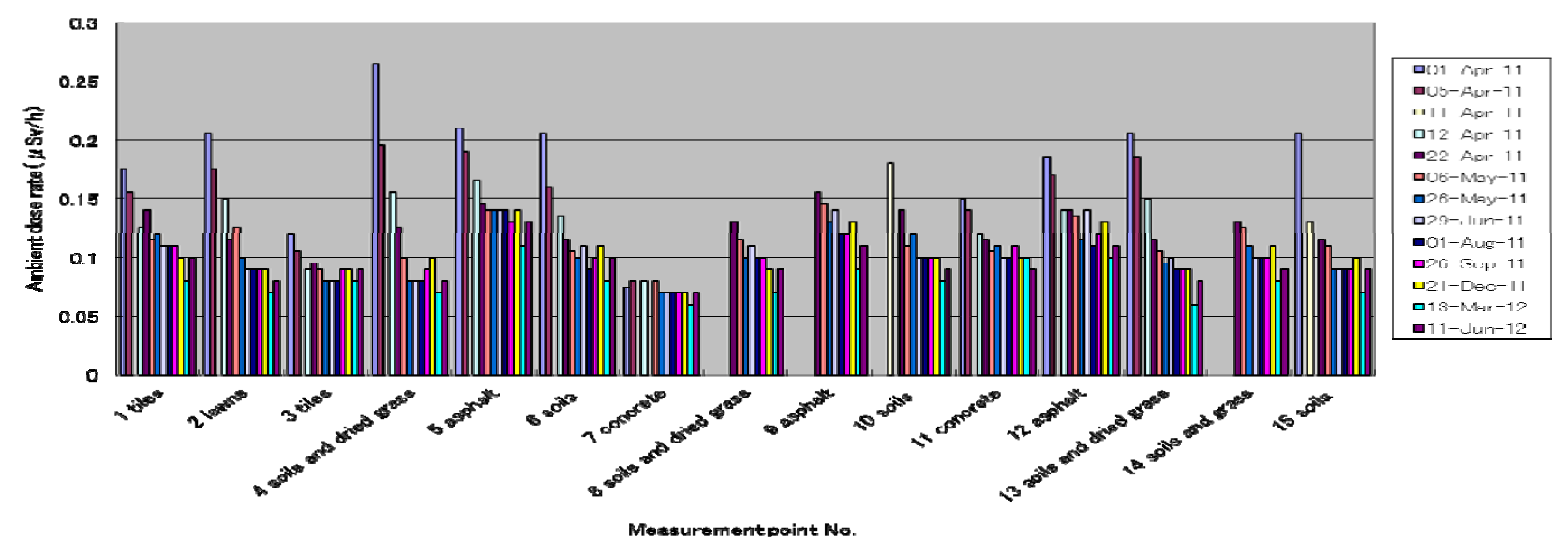

Figure 4. Ambient dose rates on ground at measurement points.

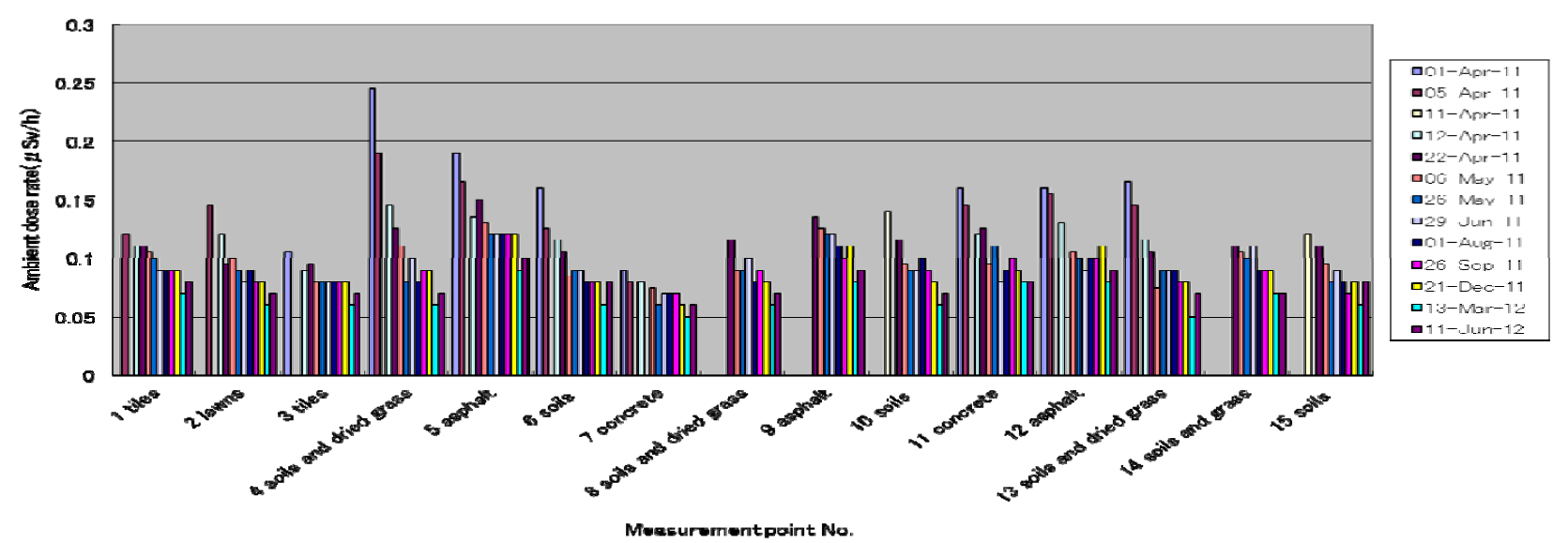

Figure 5. Ambient dose rates at 1-m height from ground at measurement points. 


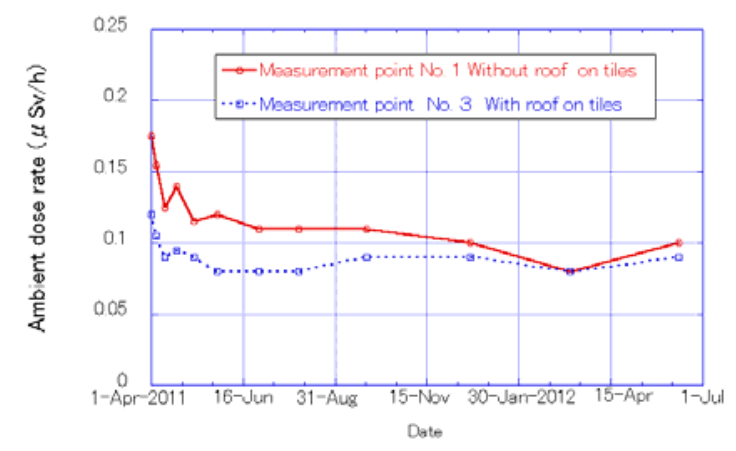

Figure 6. Comparison of ambient dose rate with and without roofs.

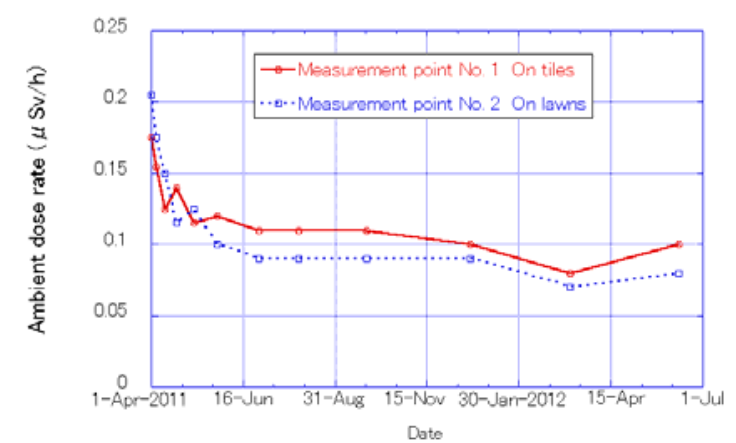

Figure 7. Comparison of ambient dose rate on tiles and on lawns.

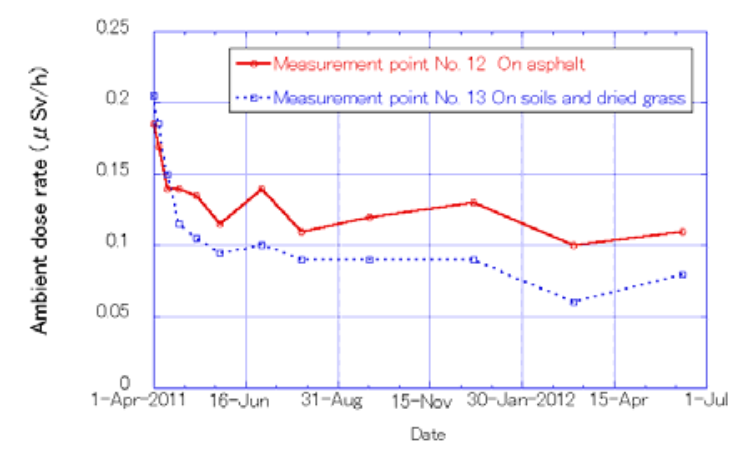

Figure 8. Comparison of ambient dose rate on asphalt and on soils with dried grass.

\section{Summary}

In this study, we have measured the radiation and radioactivity derived from the Fukushima No. 1 Power Plant at the KEK Tsukuba-campus. The dose rate decreased rapidly until May, after which it decreased gradually. The difference between the radioactivity concentrations in soils obtained on March 18 and April 1, 2011 , indicated that rain carrying radioactive materials

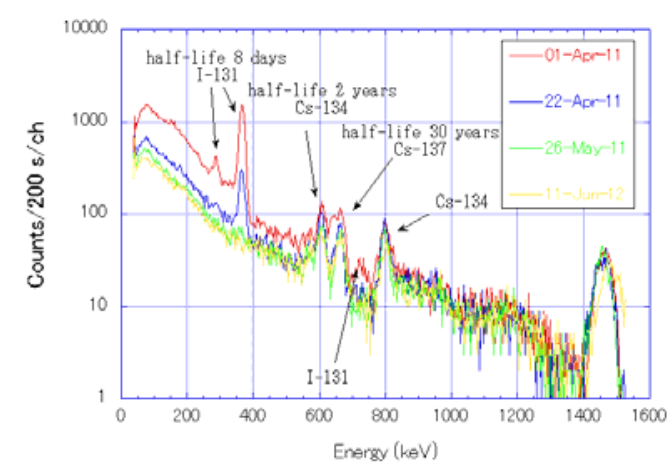

Figure 9. Gamma ray spectrum at measurement point No. 4.

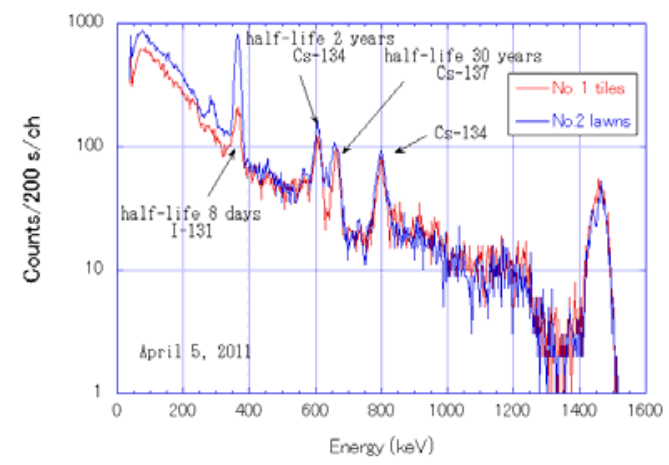

Figure 10. Gamma ray spectrum at measurement point No.1 (tiles) and No.2 (lawns) on April 5, 2011.

fell on March 21 and 22, 2011.

\section{Acknowledgements}

The authors wish to thank the staff of the Tokyo Nuclear Service for helping with the radiation measurements.

\section{References}

[1] T. Sanami, S. Sasaki, K. Iijima, Y. Kishimoto and K. Ssito, Time Variations in Dose Rate and $\gamma$ Spectrum Measured at Tsukuba City, Ibaraki, due to the Accident of Fukushima Daiichi Nuclear Power Station, Transactions of the Atomic Energy Society of Japan 10 (3) (2011), pp. 163-169.

[2] T. Doi, K. Masumoto, A. Toyoda, A. Tanaka, Y. Shibata and K. Hirose, Anthropogenic Radionuclides in the Atmosphere Observed at Tsukuba: Characteristics of the Radionuclides Derived from Fukushima, Journal of Environmental Radioactivity 122 (2013), p. 55. 